\title{
The Use of Some Techniques of Morphological Examination in Diagnosis of Some Endoparasitosis in Cattle
}

\author{
Octavian NEGREA, Vioara MIREŞAN*, Camelia RĂDUCU, Grigore ONACIU, Zamfir MARCHIŞ, \\ Mircea IGNAT, Daniel COCAN \\ Faculty of Animal Science and Biotechnologies, University of Agricultural Sciences and Veterinary \\ Medicine, 3-5 Mănăştur Street, 400372 Cluj-Napoca, Romania \\ *Corresponding author, email: vmiresan@yahoo.com
}

Bulletin UASVM Animal Science and Biotechnologies 71(2) / 2014,

Print ISSN 1843-5262; Electronic ISSN 1843-536X

DOI: $10.15835 /$ buasvmcn-asb:10784

\begin{abstract}
The morphopathological research performed on organs (liver, lungs, and mesenteric lymphonodules) prelevated from 51 cattle individuals (21 youngs and 30 adults), slaughtered during January - June 2014 in SC ROXMONT TRADING SRL slaughter house from IARA village, county of CLUJ, concerning the incidence of some digestive and lung endoparasitosis, as well as produced lesional picture. It emphasizes the incidence of cronic fasciolosis with different values, from $9.5 \%$ (in young) up to $16.6 \%$ (in adults), being in correlation to cattle grazing areas high dry land areas or low marshy areas, rich in aquatic gastropods, intermediate hosts in the life cycle of the parasite Fasciola hepatica. The hepatic and lung ehinococcosis have a different incidence with variation function of age category. Thus, in young the incidence, in both localizations (liver and lungs) have identic values from $28.5 \%$; in adults values are different, $50 \%$ located in liver and $66.6 \%$ located in lungs.
\end{abstract}

Keywords: incidence, fibrosis, parasitism, echinococcus, lymphonodule

Introduction. The Control of parasitic diseases in animals has a chance only if a correct diagnosis, by specifying, is performed, and for obtaining it, it is necessary the exact knowledge of morphology and biology of the parasites species. The diagnosis of each disease is based on the clinical picture, but also mastery assignment of common laboratory procedures. For these reasons in the present paper we proposed a study on some techniques of morphological examination in the diagnosis of some severe endoparasitosis in cattle.

Material and method. The research was performed during January - June 2014 in SC ROXMONT TRADING SRL slaughter house from IARA village, county of CLUJ. Organs were harvested immediately after the cattle slaughter-liver, lung and mesenteric lymphonodular masses- from 51 cattle (21 youth up to 3 years and 30 adults) of various breeds (Bălțata Românească, Hollstein crossbreeds and Pinzgau of Transylvania). For more accurate diagnosis there were used both methods of cutting multiple bodies and methods of kneading and passive sedimentary.

Results and discussion. By necropsy investigations carried out on a number of 51 liver masses, for fasciolosis diagnosis there were obtained the following values (Tab. 1). From the data obtained and presented in the table below it shows that the incidence of fasciolosis in cattle has different values depending on age. Thus, out of the 21 liver masses derived from cattle youth slaughtered, just 2 samples were positive, (9.5\%), and of the 30 liver masses derived from adult male a number of 5 samples were positive (16.6\%). Overall, from the 51 liver masses examined 7 samples were positive highlighting the incidence of fasciolosis. 
The necropsic examination carried out on liver masses parasited with Fasciola hepatica reveals the presence of an array of serious injuries rendered through fibro-calcareous angiocholitis hepatic hypertrophy and hepatic cirrhosis, in correlation with the number of parasites present in the bile ducts. The incidence of hepatic echinococcosis in cattle group by age categories) slaughtered in reported period is presented in table 2 . Analyzing the results obtained results that the incidence of hepatic echinococcosis in youth $(28.5 \%)$ is lower than in adults $(50 \%)$.

Tab. 1. The incidence of fasciolosis and lesional picture in cattle slaughtered in slaughtering house

\begin{tabular}{cccc}
\hline Category & No. of & \multicolumn{2}{c}{ Of which: } \\
\cline { 3 - 4 } & samples & Positive & $\%$ \\
\hline Young & 21 & 2 & 9.5 \\
\hline Adult & 30 & 5 & 16.6 \\
\hline Total & 51 & 7 & 13.7 \\
\hline
\end{tabular}

Tab. 2. The incidence of hepatic echinococcosis in slaughtered cattle

\begin{tabular}{cccc}
\hline Category & No. of & \multicolumn{2}{c}{ Of which: } \\
\cline { 3 - 4 } & samples & Positive & $\%$ \\
\hline Young & 21 & 6 & 28.5 \\
\hline Adult & 30 & 15 & 50.0 \\
\hline Total & 51 & 21 & 41.1 \\
\hline
\end{tabular}

Echinococcosis is a serious matacestodosis whose primary source of occurrence is the dogs, especially those of security guards from cattle stocks, flocks of sheep and goats, those near slaughterhouses, but alo fox and wolf. The data obtained by necropsic examination concerning the incidence and intensity of parasitism with hydatic pulmonary cystis are presented in following table (Tab. 3). From the analysis of the table joined results that the incidence of pulmonary echinococcosis in cattle vary according to age. Thus, in young cattle it is of $28.5 \%$, while in adult $66.6 \%$. The presence of hydatic pulmonary cysts are characterized by the appearance of a chronoic syndrome characterized by repeated coughing, dyspnea, asmathiform and choking crisis and by cysts breaking, death occurs in a short time through anaphylactic shock.

Tab. 3. The incidence and intensity degree of lung echinococcosis in cattle slaughtered in slaughtering house

\begin{tabular}{cccc}
\hline Category & No. of & \multicolumn{2}{c}{ Of which: } \\
\cline { 3 - 4 } & samples & Positive & $\%$ \\
\hline Young & 21 & 11 & 52.3 \\
\hline Adult & 30 & 19 & 63.3 \\
\hline Total & 51 & 30 & 58.8 \\
\hline
\end{tabular}

Tab. 4. The incidence of visceral (lymponodular mesenteric) linguatulosis in cattle slaughtered in slaughtering house

\begin{tabular}{cccc}
\hline Category & No. of & \multicolumn{2}{c}{ Of which: } \\
\cline { 3 - 4 } & samples & Positive & $\%$ \\
\hline Young & 21 & 6 & 28.5 \\
\hline Adult & 30 & 20 & 66.6 \\
\hline Total & 51 & 26 & 50.9 \\
\hline
\end{tabular}

The incidence of the metalinguatulosis (visceral linguatulosis) in slaugthered cattle as results of necroscopic investigations of the mesenteric lymphonodular mass, by age categories, is presented in the following table (Tab.4). The analysis of the data obtained and presented in the table above results that incidence of mesenteric lymphonodular linguatulosis presents significant values. Thus, in young cattle the presence of the mesenteric lymphonodular linguatulosis is $52.3 \%$ and in adults is $63 \%$. Research concerning both rhynosinusal and mesenteric lymphonodular linguatulosis performed at national level and in Transylvania emphasizes values of $4.4 \%$ rhynosinusal linguatulosis in carnivores, and $47.4 \%$ and mesenteric lymphonodular linguatulosis in cattle.

Conclusion. The morphopatological research performed on organs organs (liver, lungs, and mesenteric lymphonodules), concerning the incidence of some digestive and lung endoparasitosis, as well as produced lesional picture, emphasize the following aspects: 1.The incidence of fascilosis emphasizes different values being in correlation with cattle grazing areas, on high areas with dry fields or on low swampy areas, rich in aquatic gasteropods, intermediary hosts of biological cycle of the parasite Fasciola hepatica; 2. The hepatic and pulmonary echinococcosis had a different incidence with variation function of age category; 3. For the mesenteric lymphonodular linguatulosis was obtained an incidence of $52.3 \%$ in young individuals and $63.3 \%$. in adults.

\section{REFERENCES}

1. Andrew AH, Blowey RW, Boyd H and Eddy RG (2004). Bovine Medicine (Second edition), Blackwell Publishing.

2. Negrea O (2003). Linguatuloza la erbivore şi carnivore. Ed. AcademicPres Cluj-Napoca.

3. Şuteu I, V Cozma (2007). Parazitologie clinică veterinară, Vol I, II. 